\title{
Method of SAR sounding signals investigation and digital forming
}

\author{
Anna Tarasenko* \\ JSC Radio Engineering Company "Vega”, 121170, Moscow, Russia
}

\begin{abstract}
The article describes modern approaches to the choice and synthesis of modulating functions used for various purpose radio system signal generation.
\end{abstract}

\section{Introduction}

Synthesized (or, more often called, synthetic) aperture radars (SAR) tend to occupy the more significant position as a facility of remote Earth sensing [1]. This fact can be explained with SAR having a set of advantages such as providing high spatial resolution by range and azimuth comparable with that of optical instruments, availability of various survey modes and radar data processing algorithms, independence on daytime and weather conditions, operability.

The wider is the scope of problems to solve using radar images, the vaster is the circle of customers requiring not only high radar resolution and image quality but also possibility of obtaining exact geometry of ground objects and their mutual position, electrodynamical and radiometrical properties of the terrain.

The purposes of SAR mission and the priority of problems it is designed to solve determine sounding signal parameters such as carrier frequency, bandwidth, modulation type and pulse repetition frequency [2].

\section{Why we need to choose sounding signal modulation}

Correct choice of radar signal parameters is a key point in designing such a complex system as synthetic aperture radar [3]. It is worth mentioned that SAR sounding signal, unlike that of general radar, is a series of properly modulated pulses.

The question of sounding signal implication on SAR principal performances, in particular, on its range resolution and radiometric characteristics (resolution, sensitivity and dynamic range). Single point target image is considered as radar impulse response and chosen as the criterion of SAR test result analysis. Two-dimensional response main lobe width at $-3 \mathrm{~dB}$ level, maximum amplitude, peak sidelobe ratio (PSLR) and integral sidelobe level (ISLR) are analyzed. Main lobe level is responsible for SAR energetic characteristics, spatial resolution depends on main lobe width, and radiometric performances can be explained in terms of integral sidelobe level.

*Corresponding author: asianna@list.ru 
Radar signal phase modulation types can be subdivided in 2 principal types such as continuous and discrete. In practice, the most often used type of continuous modulation is linear frequency modulation (LFM), and those of discrete are phase-code modulated signals.

LFM signal (chirp) is a typical kind of sounding signal in most modern spaceborne Earth sensing SARs. Examples of using phase-coded pulses are known as well. Periodically repeated 127-bit M-sequence, for example, has been used for remote mapping of Venus from "Venera-15" and "Venera-16" spacecrafts [4]. 64-bit pseudo-random binary sequence (PRBS) has been chosen for the experiment "Magellan" on mapping of Venus surface [5]. M-sequence is used by American scientists for radar mapping of the Moon and planets from the Earth [6].

Since SARs primarily were applied for the tasks of detection, where high signal-tonoise ratio and good spatial resolution have been the main requirements, the criteria of sounding signal choice have been its auto-correlation function main lobe width and nearest sidelobe levels. As for chirp, in spite of its response function having high first sidelobes ($13 \mathrm{~dB}$ ), their position is well known, and they can be rejected by means of weight functions such as Hamming window [7, p.63], the problem of integral sidelobe suppression being solved as well. As for phase-coded pulses modulated with M-sequence, their response function peak sidelobes are remote from the main lobe, and their peak levels depending upon sequence length are much less than those of the chirp. The properties above provide some advantages of using phase-coded pulse as a sounding signal for obtaining better SAR image detail distinction. However, M-sequences have some drawbacks. In particular, there is no known way of sidelobe filtering because their appearance can't be expressed analytically with any simple function.

At present, when distributed terrain characteristic measurement quality obtained from SAR images become of the more interest due to their being applied for a number of tasks such as monitoring of arctic ice situation, river overflows, sea and terrain pollutions, forest and agriculture health, the problem of improving SAR radiometric characteristics by means of decreasing integral response sidelobe level becomes of special actuality.

\section{How to choose sounding signal modulation}

At present, when distributed terrain characteristic measurement quality obtained from SAR images become of the more interest due to their being applied for a number of tasks such as monitoring of arctic ice situation, river overflows, sea and terrain pollutions, forest and agriculture health, the problem of improving SAR radiometric characteristics by means of decreasing integral response sidelobe level becomes of special actuality.

There are a lot of different function to modulate signal, some of them was proposed by author [8] and presented in the table 1.

There is no one answer to the question which signal type is better, by the reason that choice depends on purpose of designed system and due to new functions for signal modulation. By this reason, method that allows to investigate various types of signals, to evaluate their practical feasibility and make an informed choice of them had been developed and presented below.

1. Choice of a modulating function or a family of such functions which planned to analyse.Investigation of one-dimensional ACF of modulating function to assess applicability for the required problem solving.

2. Building a digital model of a modulating functions family (in the Matlab for example) according to sampling frequency and, if necessary, adapted to the characteristics of the transmit-receive path of the designing SAR.

3. Synthesis of the two-dimensional response function in the range-azimuth coordinates or the two-dimensional ambiguity function in the range-speed coordinates (for the pulse- 
Doppler locator) from the signal's digital model. Analysis of a two-dimensional function according to the criteria of the main lobe width (determine resolution), maximum, integral level and location of the side lobes.

4. Construction of a sounding signal digital model taking into account the generator characteristics.

5. Formation of a data file in a format that signal generator support (to work on a stand), or a binary file to save in radio sensor long-term memory.

6. Generation of a signal from digital model, recording the same signal through a hardware loop, saving a digital radio hologram. Compression of the radio hologram by range and azimuth.

7. Two-dimensional hardware response function analysis.

Table 1. Modulation functions and characteristics provided by them.

\begin{tabular}{|c|c|c|c|}
\hline Modulation type & Side lobe distribution & PSLR, dB & ISLR, dB \\
\hline $\begin{array}{l}\text { Random alternating } \\
\text { and random bias of } \\
\text { M-sequences }\end{array}$ & uniform & $-52,4$ & $-5,1$ \\
\hline $\begin{array}{l}\text { Stochastic functions } \\
\text { (m-position phase } \\
\text { modulation and } \\
\mathrm{m}^{2} \text {-position QAM) }\end{array}$ & uniform & $-52,2$ & $-2,6$ \\
\hline Legendre sequence & uniform & $-51,9$ & $-8,3$ \\
\hline $\begin{array}{l}\text { Random alternating } \\
\text { and linear bias of } \\
\text { M-sequences }\end{array}$ & uniform & $-47,0$ & $-5,2$ \\
\hline $\begin{array}{l}\text { Random bias of one } \\
\text { M-sequence }\end{array}$ & $\begin{array}{c}\text { located on main } \\
\text { azimut cross section }\end{array}$ & $-53,8$ & $-5,1$ \\
\hline $\begin{array}{c}\text { LFM/LFM with } \\
\text { Hamming window }\end{array}$ & $\begin{array}{c}\text { located on main cross } \\
\text { sections }\end{array}$ & $-13,6 /-42,3$ & $-7,5 /-10,2$ \\
\hline $\begin{array}{l}\text { Periodic alternating } \\
\text { and liear bias of } \\
\text { M-sequences }\end{array}$ & Periodic stripes & $-41,2$ & $-5,2$ \\
\hline $\begin{array}{l}\text { Random alternating } \\
\text { of M-sequences }\end{array}$ & $\begin{array}{l}\text { Maximum side lobe } \\
\text { are on main azimut } \\
\text { cross section }\end{array}$ & $-40,6$ & $-5,3$ \\
\hline $\begin{array}{l}\text { Linear bias of one } \\
\text { M-sequence }\end{array}$ & $\begin{array}{l}\text { located near main } \\
\text { azimut cross section }\end{array}$ & $-38,2$ & $-5,2$ \\
\hline $\begin{array}{l}\text { Periodic alternating } \\
\text { of M-sequences }\end{array}$ & Periodic stripes & $-36,3$ & $-5,4$ \\
\hline $\begin{array}{l}\text { One M-sequence } \\
\text { (without bias and } \\
\text { alternating) }\end{array}$ & $\begin{array}{l}\text { located on main } \\
\text { azimut cross section }\end{array}$ & $-28,4$ & $-5,4$ \\
\hline
\end{tabular}

Thus, in accordance with the proposed method, the choice of modulating functions, the compilation of digital models based on them and the analysis of model response functions can be implemented before or at the initial stages of SAR development, that will allow to estimate expected image characteristics which can be obtained with selected signal type. Radio signals generation and comparative analysis of hardware and model response functions will allow to estimate the distortions introduced by the equipment. 


\section{References}

1. M.I. Skolnik, L.B. Neronskiy, I.G. Osipov, V.E. Turuk, Radar Handbook, McGrawHill (1970)

2. R.O. Harger, Synthetic Aperture Radat Fundamentals and Image Processing, EARSeL advances in remote sensing, 2, No.1-1, (1993)

3. D.E. Vakman, R.M. Sedleckij, Problems of radar signal synthesis, Moscow (1973)

4. N. Levanon, E. Mozeson, Radar Signals, New Jersey: John Wiley \& Sons (2004)

5. A.I Zakharov., Integral SAR dignal sidelobe implication on measurement quality, Available: http://www.mivlgu.ru/conf/armand2012/pdf/S4_10.pdf. [Accessed 20 September 2019]

6. A.I. Kudrya, E.F. Tolstov, V.N. Chetverik, Extensed possibilities of using M-sequences in SAR. Available: http://www.mivlgu.ru/conf/armand2012/pdf/S4_20.pdf. [Accessed 20 September 2019]

7. S.L.Vnotchenko, M.Ju. Dostovalov, V.S. Dudukin, A.I. Kovalenko, T.G. Musinjanc, V.V. Riman, A.I. Seljanin, S.N. Smirnov, A.V. Shishanov, Space Radar "Severyanin$M^{\prime \prime}$ with wide acquisition range, EUSAR, p. 422 (2012)

8. A.M. Tarasenko, Researching of radar image quality dependence on sounding signal generation mode for spaceborne SAR, Achievements of Modern Radioelectronics, 5, pp. 13-19 (2015) 